\title{
Atomization characteristics of multi-type aerial nozzles in wind tunnel and low airflow velocity condition in manned agricultural helicopter
}

\author{
Weixiang Yao ${ }^{1,2}$, Yubin Lan ${ }^{2,3^{*}}$, Wesley Clint Hoffmann ${ }^{4}$, Shuang Guo ${ }^{1,2}$, Shengde Chen ${ }^{2,3}$, \\ Sheng Wen ${ }^{2,5}$, Wen Zeng ${ }^{1,2}$, Zhihong $\mathrm{Li}^{1,2}$, Xiaowen Liang ${ }^{6}$ \\ (1. College of Engineering, South China Agricultural University, Guangzhou 510642, China; \\ 2. National Center for International Collaboration Research on Precision Agricultural Aviation Pesticides Spraying Technology (NPAAC), \\ Guangzhou 510642, China; \\ 3. College of Electronic Engineering, South China Agricultural University, Guangzhou 510642, China; \\ 4. Prology Consulting LLC, College Station, Texas 77845, USA; \\ 5. Engineering Fundamental Teaching and Training Center, South China Agricultural University, Guangzhou 510642, China; \\ 6. Jiangxi Tianren Ecology Co., Ltd, Jian 343100, China)
}

\begin{abstract}
In order to explore the atomization characteristics of the LICHENG series nozzle for manned agricultural helicopter under medium and low airflow velocity conditions, droplet size tests on five sizes of nozzles 11002, 11003, 11004, 11006 and 11010 were carried out by laser diffraction device (LDD), based on the high-low speed composite wind tunnel for agricultural aviation designed by the National Center for International Collaboration Research on Precision Agricultural Aviation Pesticides Spraying Technology (NPAAC) of South China Agricultural University (SCAU). The results showed that under the three spray pressures of 30,40 and $50 \mathrm{psi}$, the droplet sizes of the five types of nozzles expressed similar trends with the increase of airflow velocity. Among them, the droplet size variation of nozzles 11006 and 11010 with larger orifice size was the most significant, the largest range of Dv0.1 was nozzle 11010, and the largest range of Dv0.5 and Dv0.9 was nozzle 11006 . In addition, the changes of spray pressure would directly affect the quality of spray, especially the nozzles 11002, 11003 and 11004 with small orifice sizes were significantly affected. Under the condition of medium and low airflow velocity of $0-27.8 \mathrm{~m} / \mathrm{s}, 89 \%$ of spread value (SV) by the five nozzles were in the range of less than $15 \%$, but there were some test nozzles with poor spray stability during the test, which made the measurements of droplet size value larger, resulting in a maximum test deviation of up to $210.9 \mu \mathrm{m}$. The result also exposed the limitations exist in wind tunnel droplet size testing by using LDD, and an increase in airflow velocity resulted in a larger measurement droplet size. This phenomenon was particularly significant in the Dv0.5 test results of various types of nozzles. This study can provide experimental data guidance for the optimization design and parameter selection of aerial nozzle for manned agricultural helicopter.
\end{abstract}

Keywords: manned helicopter, aerial nozzle, wind tunnel, droplet size, agricultural application, spray classification DOI: $10.33440 /$ j.ijpaa.20190201.0031

Citation: Yao W X, Lan Y B, Hoffmann W C, Guo S, Chen S D, Wen S, et al. Atomization characteristics of multi-type aerial nozzles in wind tunnel and low airflow velocity condition in manned agricultural helicopter. Int J Precis Agric Aviat, 2019; 2(1): 9-17.

\section{Introduction}

Aerial spraying has the advantages of high working efficiency and the ability to rapidly treat large areas, which ground machinery

Received date: 2019-10-10 Accepted date: 2019-10-20

Biographies: Weixiang Yao, Doctoral student, research interests: precision agriculture aviation technology and equipment, Email: 1913835329@qq.com; Wesley Clint Hoffmann, $\mathrm{PhD}$, research interests: agricultural aerial applications. Prology Consulting LLC, College Station, TX 77845, USA, Email: clint.hoffmann@gmail.com; Shuang Guo, Postgraduate student, research interests: agriculture aviation technology, Email: 2358681011@qq.com; Shengde Chen, $\mathrm{PhD}$, research interests: precision agriculture aviation, Email: 1163145190@qq.com; Sheng Wen, PhD, Associate Professor, research interest: precision agricultural aviation application, Email: 58675023@qq.com; Wen Zeng, PhD, research interests: precision agriculture aviation, Email: zengwen@scau.edu.cn; Zhihong Li, Doctoral student, Technician, research interests: precision agriculture technology and equipment, Email: 402602144@qq.com; Xiaowen Liang, Agronomist, research interests: plant protection, Email: xiaowen@jxtianren.com.

* Corresponding author: Yubin Lan, PhD, Distinguished Professor, Director, research interests: precision agricultural aviation application, Email: ylan@scau.edu.cn. cannot achieve. However, spray drift can occur in practice due to the influence of application conditions and airflow ${ }^{[1-3]}$. Pesticide drift refers to a physical movement of droplets in the air from the target area to non-target area during the application ${ }^{[4]}$. Droplets size is one of the important factors affecting the droplet drift, and the secondary breakup of droplets resulting from high air velocity will occur simultaneously. Therefore, it is necessary to test the droplet size of the aerial nozzles in detail ${ }^{[5-6]}$. The common methods for testing droplet size mainly include flight test in field and wind tunnel test. The field test is susceptible to external environmental conditions, and the test costs are higher. The wind tunnel test can simulate the real flight environment and accurately control parameters such as wind velocity and direction and is commonly used in research of droplet size ${ }^{[7-9]}$.

Some efforts are being made by foreign scholars for the atomization characteristics of aerial nozzles in wind tunnel tests. Guler et al. ${ }^{[10]}$ compared the droplet size distributions and spray pattern widths of air induction flat-fan nozzle and conventional extended range flat-fan nozzle at low wind velocities of not more than $5.0 \mathrm{~m} / \mathrm{s}$ in wind tunnel. Kirk ${ }^{[11]}$ conducted a series of particle size fitting tests on eleven hydraulic nozzles, which were used on 
fixed-wing aircraft in a high-speed wind tunnel with a wind velocity of 45-69 m/s. Eleven spray nozzle atomization models were developed for spray nozzles in common use in the fixed-wing agricultural aviation industry in the U.S., which were demonstrated to provide reasonable estimates of spray droplet spectra parameters. Hoffmann et al. ${ }^{[12]}$ evaluated droplet size spectrum characteristics of two spray nozzles using three different droplet size measurement systems in a high-speed wind tunnel at airspeeds of 45 and $58 \mathrm{~m} / \mathrm{s}$. The results showed that there were significant differences between the droplet size values reported by the three measurement systems, but they had considerable agreement trends. Based on Kirk's research, Fritz et al. ${ }^{[13-14]}$ updated the USDA-ARS fixed-wind spray nozzle models to make it more applicable, then conducted studies to determine the repeatability and accuracy of droplet size from a standardized set of spray nozzles at three different application technology research laboratories. It was found that the three laboratory measurements of drop size varied by less than $5 \%$.

There has been rapid development of China's agricultural aviation industry with agricultural aviation aircraft represented by unmanned aerial vehicle (UAV), manned helicopters and manned fixed-wing aircraft. The spray characteristics of aerial nozzles have also been concerned simultaneously ${ }^{[15]}$. However, due to the limitation of geographical conditions, agricultural production layout and policy regulations, the three types of aircraft usually have different operating ranges of velocity. UAVs are more suitable for small scattered fields and the working velocity is in the low-velocity category, usually no more than $8 \mathrm{~m} / \mathrm{s}$. Manned helicopters are suited for hilly and mountainous areas; the flight velocity is usually in the medium-low velocity range of $15-30 \mathrm{~m} / \mathrm{s}$. The manned fixed-wing aircraft apply to large-area concentrated fields, which operation velocity is usually in the medium-high velocity range of $30-80 \mathrm{~m} / \mathrm{s}^{[16-18]}$. China has carried out relevant wind tunnel test research work on various types of agricultural aviation aircraft-specific nozzle at present, but there is still a gap compared with foreign in terms of quantity and systematic ${ }^{[19]}$. In addition, the wind tunnel test mainly focused on the low-velocity range for $\mathrm{UAV}^{[20,21]}$ and the medium-to-high-velocity range for manned fixed-wing aircraft ${ }^{[22-24]}$. The reported research on the spray droplets characteristics of manned helicopters, which operate with low to medium velocities, is minimal and the reason for this research report.

This paper aims to measure flat-fan-shaped nozzles commonly

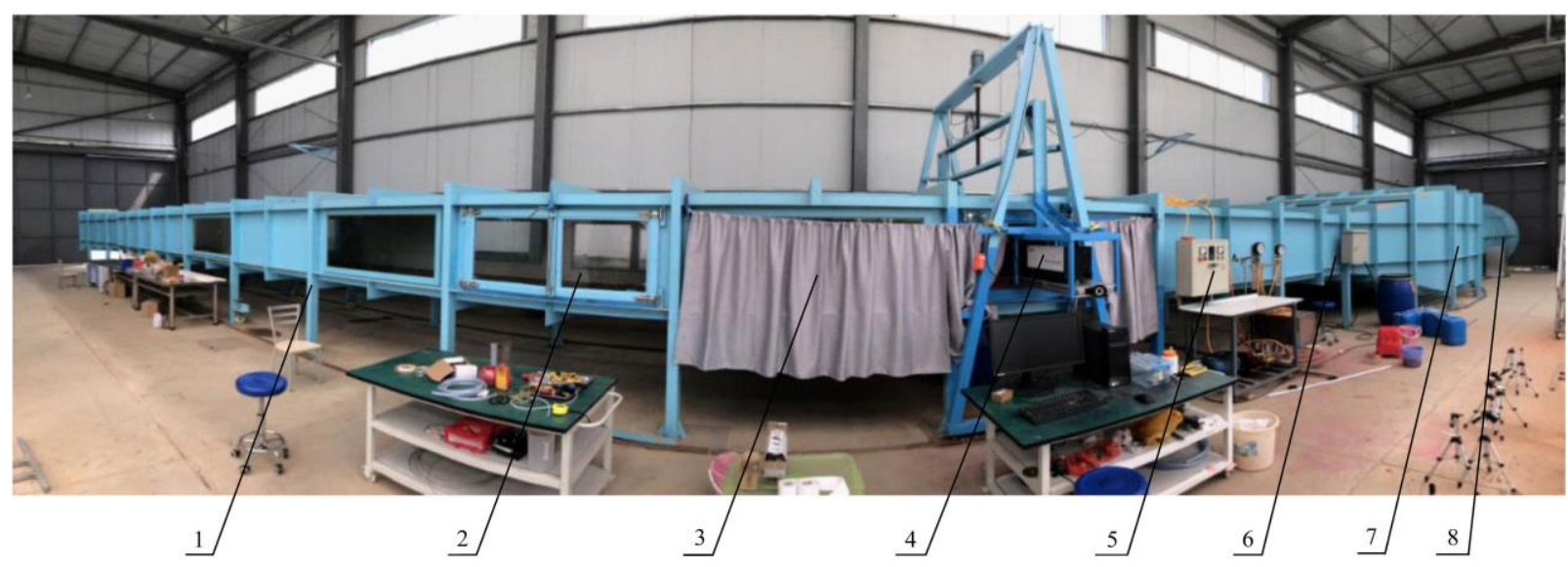

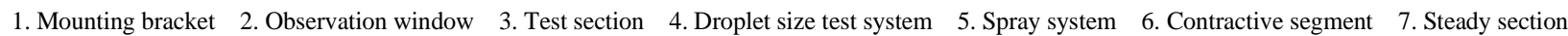
8. Drive section

Figure 1 Structure diagram of SCAU wind tunnel

The spray system used in the test was a spray control system independently designed by the NPACC. The system included a used in manned agricultural helicopters in China under simulated low and medium airflow velocity conditions of helicopter operation in the high-low speed composite wind tunnel for agricultural aviation. Different spray pressures were set, and a DP-02 laser diffraction device (LDD) was used to measure the droplet size change after spraying, then evaluated the atomization characteristics of flat-fan-shaped nozzles under medium and low airflow velocity conditions. This study of the wind tunnel is of great significance to optimize the aviation application program and provide a reference for reducing the drift of aerosol spray operation.

\section{Materials and methods}

\subsection{Wind tunnel}

The wind tunnel used in this test is the high-low speed composite wind tunnel for agricultural aviation in the National Center for International Collaboration Research on Precision Agricultural Aviation Pesticides Spraying Technology (NPAAC) of South China Agricultural University (SCAU) in Guangzhou, Guangdong Province, China. The SCAU wind tunnel is based on the ISO 22856 standard $^{[25]}$. The body of the wind tunnel is all-steel structure; the observation window and spray operation platform are arranged on both sides. A spray track with a movable adjustment is arranged in the wind tunnel, which can meet the requirements of a conventional spray test. The tester can also enter the test section of wind tunnel from the observation window to change spray nozzles. The detailed parameters of the wind tunnel are shown in Table 1, and the wind tunnel structure can be seen in Figure 1.

Table 1 Parameters of SCAU wind tunnel

\begin{tabular}{lc}
\hline \multicolumn{1}{c}{ Main parameter } & Norms and numerical \\
\hline Diameter of test section $/ \mathrm{m} \times \mathrm{m} \times \mathrm{m}$ & $20 \times 2.0 \times 1.1$ \\
Wind velocity $/ \mathrm{m} \cdot \mathrm{s}^{-1}$ & $2 \sim 52$ \\
Turbulence intensity $/ \%$ & $<1$ \\
Axial static pressure gradient & $<0.01$ \\
Dynamic pressure stability coefficients $/ \%$ & $<1$ \\
Averaged flow inclination angle $/\left({ }^{\circ}\right)$ & $<1$ \\
\hline
\end{tabular}

water tank, boost pump, relief valve, pressure reducing valve, flow meter, pressure gauge and nozzles. The spray pressure was 
adjusted by a two-stage pressure regulating method of relief valve and pressure reducing valve. The relief valve pressure was set to 87-102 psi (pressure gauge 1). The pressure of the pressure reducing valve was adjusted to 14-73 psi (pressure gauge 2) according to the spray pressure. The schematic of the spray system is as Figure 2.

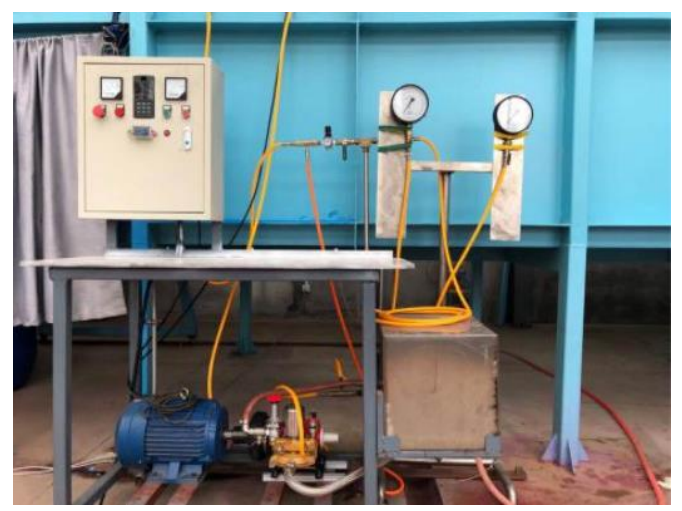

a. Spray system appearance

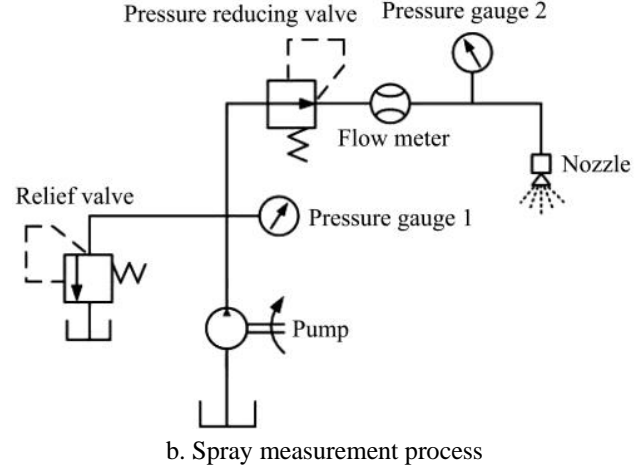

Figure 2 Schematic diagram of the spray system and spray measurement process

\subsection{Nozzles tested}

All nozzles used for wind tunnel tests were LICHENG standard flat fan tips in polymer (Yuyao LICHENG Mould Factory, China). Five nozzle sizes were selected, namely 11002, 11003, 11004, 11006 and 11010 and all test nozzles were brand new without wear. These nozzles are designed to create a spray fan angle of $110^{\circ}$ and the flowrates for the nozzles were $0.2,0.3,0.4$, 0.6 and $1.0 \mathrm{gpm}$ at $40 \mathrm{psi}$. The nozzles are shown in Figure 3.

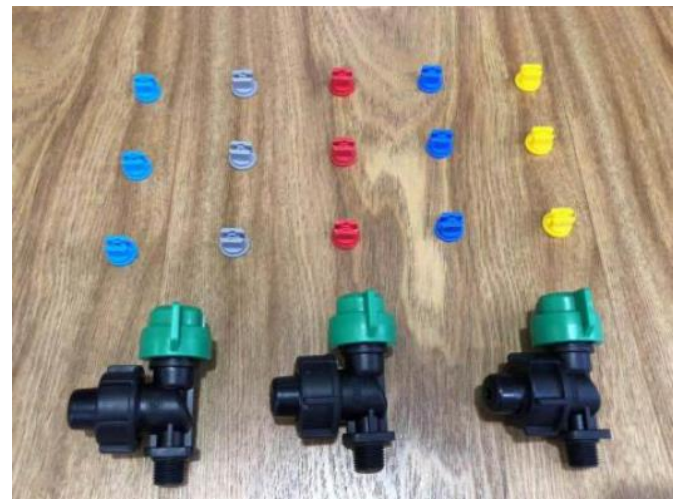

Figure 3 Test nozzles

The droplet size distribution was measured by DP-02 LDD (Zhuhai OMEC Instrument Co., Ltd, Zhuhai, China). The output power of LDD is 2-3.5 mw, with the wavelength of $0.6328 \mu \mathrm{m}$, the number of independent detection units of 48 , and the measurement range of $1-1500 \mu \mathrm{m}$. The median diameter repeatability of LDD is $\pm 3 \%$, and the data sampling analysis time was less than 2 min for each tests.

\subsection{Experiment design}

The LDD and test nozzles arrangement in the wind tunnel is shown in Figure 4. The distance between the transmitter and receiver of LDD was $190 \mathrm{~cm}$, which were placed horizontally on the special working platform at the observation window on both sides of the wind tunnel test section. The nozzles were placed horizontally, and the distance from the upper and lower layers of the wind tunnel was $55 \mathrm{~cm}$. Droplet size measurements were made with a distance of $40 \mathrm{~cm}$ between the nozzle outlet and the laser.

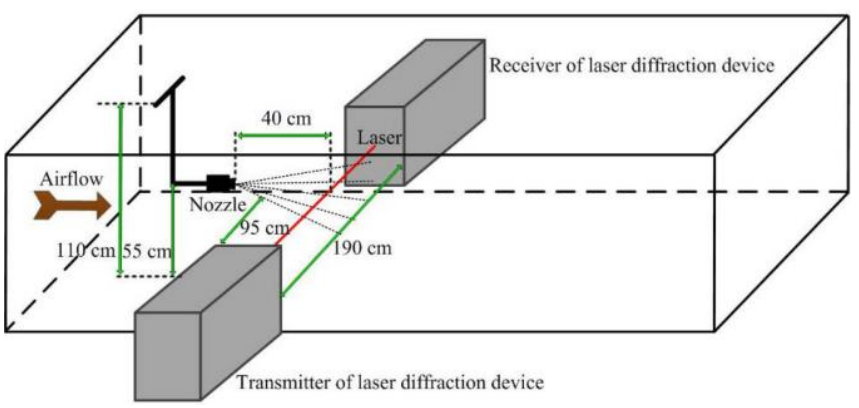

Figure 4 Schematic of experiment design in wind tunnel

The test set six wind tunnel test airflow velocities of $0,16.7$, $19.4,22.2,25.0$ and $27.8 \mathrm{~m} / \mathrm{s}$, and spray pressure of 30,40 and 50 psi. The room temperature and air humidity were kept constant during the experiment, and the test was water. The five type nozzles were sprayed under the aforementioned conditions, the same set of tests was repeated three times with a collection time of $30 \mathrm{~s}$ for each nozzle, pressure, and airflow velocity combination.

\subsection{Evaluation parameter}

The parameters evaluating the atomization performance of the nozzle are $\mathrm{D}_{\mathrm{v} 0.1}, \mathrm{D}_{\mathrm{v} 0.5}, \mathrm{D}_{\mathrm{v} 0.9}, \mathrm{~V}_{<100}$ (\% $\%_{\text {volume }}$ ), relative span (RS), and spread value (SV)[26]. The $\mathrm{D}_{\text {va }}$ values are the droplet diameters $(\mu \mathrm{m})$ where $(\mathrm{a} \times 100) \%$ of the spray volume is accumulated in droplets with diameters smaller than this value. $\mathrm{D}_{\mathrm{v} 0.5}$ is also called volume median diameter (VMD). $\quad \mathrm{V}_{<100}$ (\%volume) expresses the percent spray volume with a diameter less than $100 \mu \mathrm{m}$. RS is the span of the droplet distribution, which reflects the uniformity of the droplets sprayed by the nozzle, RS = ( $\mathrm{Dv}_{\mathrm{v} .9}-\mathrm{D}_{\mathrm{v} 0.1}$ )/Dv0.5. The smaller the RS, the better the uniformity of the droplets, $\mathrm{RS}=1$ indicating the droplet size is symmetrically distributed. SV is used to characterize the difference of the repeated measurement results in the same set of experiments, $\mathrm{SV}=$ (maximum value - minimum value) $\times 100 /$ mean value, the smaller the SV, the smaller the difference in the repeated test results of the same group.

According to ASABE Standard S572.2 $2^{[27]}$, the droplet size of each type of nozzle is graded to characterize the atomization performance. Droplet size classification category (DSC) includes Extremely Fine (XF), Very Fine (VF), Fine (F), Medium (M), Coarse (C), Very Coarse (VC), Extremely Coarse (XC) and Ultra Coarse (UC) 8 levels.

\subsection{Statistical analyses}

All the statistical analyses were performed using the SPSS 16.0 software (IBM, Chicago, USA). Means separation among individual pressure within each nozzle type was done using by Least-Significant Difference (LSD) multiple test $(\alpha=0.05)$.

\section{Results and discussion}




\subsection{Nozzle flow rates}

A flow rate test was performed on each type of nozzle before the formal wind tunnel test. The test results (Table 2) showed that the actual measured spray flow rate of all tested nozzle per unit time was close to the standard reference value under spray pressures of 30, 40 and 50 psi.

Table 2 LICHENG nozzle flow rates for the three pressures used in droplet size testing

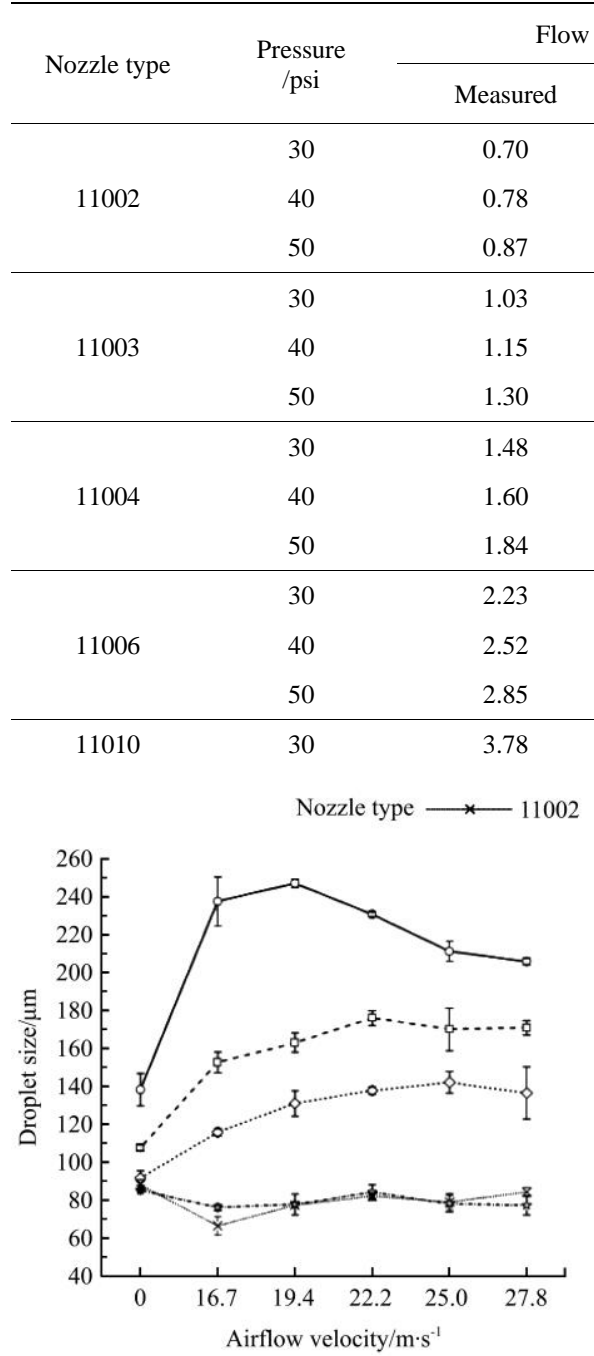

a. Spraying pressure of $30 \mathrm{psi}$

$\begin{array}{lll}40 & 4.32 & 4.30 \\ 50 & 4.80 & 4.78\end{array}$

3.2 Variation of droplet size under different airflow velocities

Spray droplet size is a critical factor in characterizing the performance of any agrochemical solution and is a reference for nozzle selection and nozzle operation. Figures 5 to 7 respectively show the changes of Dv0.1, Dv0.5 and Dv0.9 at different airflow velocities of five tested nozzles.

It was found (Figure 5) that the Dv0.1 values of five nozzles 11002, 11003, 11004, 11006 and 11010 showed similar change tendency of increasing with airflow velocity under three different spray pressures. Among them, compared with the condition of wind velocity of $0 \mathrm{~m} / \mathrm{s}$, the Dv0.1 value of nozzles 11002 and 11003 decreased with the increase of airflow velocity, while nozzles 11004, 11006 and 11010 increased with the increasing airflow velocity. In addition, the nozzle 11010 had the largest difference with the change of the airflow velocity, the range of Dv0.1 were $108.8,105.2$ and $100.5 \mu \mathrm{m}$ under the spray pressures of 30, 40 and $50 \mathrm{psi}$, respectively. It can also be found that in the middle and low airflow velocity, the range of Dv0.1 by the nozzle 11010 showed a decreasing trend with the increase of spray pressure. Further statistical analysis showed that the trend also applied to nozzles 11004 and 11006, while the nozzles 11002 and 11003 did not meet this trend, but showed a tendency to decrease after the increase.

\section{Figure 5 Variation of $\mathrm{D}_{\mathrm{v} 0.1}$ with airflow velocity}

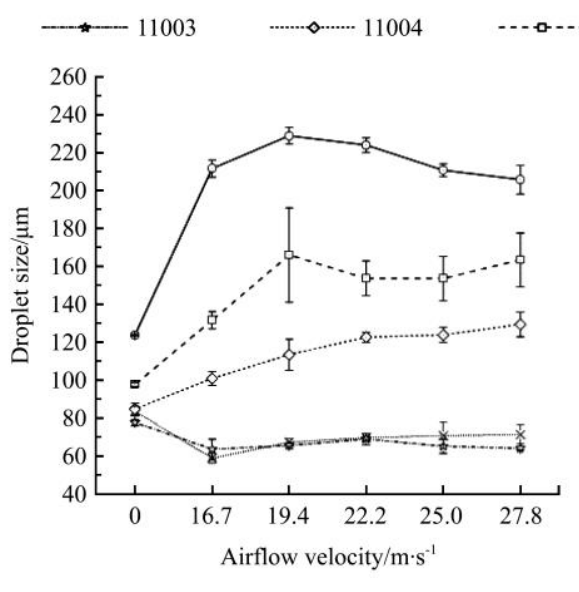

b. Spraying pressure of $40 \mathrm{ps}$

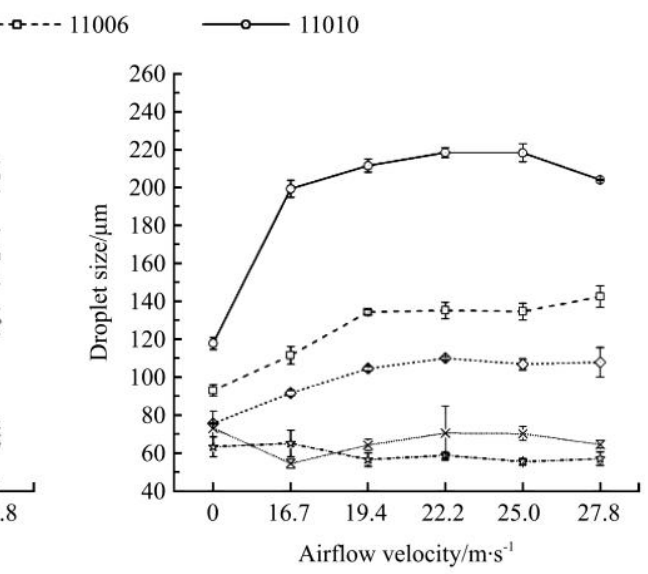

c. Spraying pressure of $50 \mathrm{psi}$
Figure 6 presents the variation of Dv0.5 with airflow velocity. It was also found that the Dv0.5 values of the five nozzles showed a similar change tendency with increasing airflow velocity for three different spray pressures. Compared with the Dv0.5 value at $0 \mathrm{~m} / \mathrm{s}$, all the five type nozzles showed the trend of increasing with airflow velocity increased. In addition, the 11006 nozzle has the largest difference with the change of airflow velocity in Dv0.5, with the ranges of $176.9,182.0$ and $140.8 \mu \mathrm{m}$ under the spray pressures of 30,40 and 50 psi, respectively, which was different from the nozzle 11010 with the largest difference analyzed in $\mathrm{D}_{\mathrm{v} 0.1 \text {. At }}$ the same time, the extreme range of Dv0.5 by the nozzle 11006 first increased then decreased with the increase of spray pressure in the middle and low airflow velocity. However, further statistical analysis showed that this trend was only applicable to the nozzle 11006, not applicable to the other types of nozzles, and the other four types of nozzles did not show any regular trends, which were not statistically significant and will not be listed here. It may be due to a performance problem with one of the three 11006 nozzles.

Finally, Dv0.9 is considered (Figure 7). The Dv0.9 values of the five nozzles also showed a similar change tendency with increasing airflow velocity under three different spray pressures. Compared with the Dv0.9 at $0 \mathrm{~m} / \mathrm{s}$, the Dv0.9 value of the nozzles 11002, 11003, 11004 and 11006 showed the trend of increasing with the airflow velocity increased, only the Dvo.9 corresponding to the nozzle 11010 showed a trend of decreasing with the airflow velocity increased. In addition, the Dv0.9 of the nozzle11006 had the largest difference with the change of the airflow velocity, with the range of $308.2,316.2$ and $227.4 \mu \mathrm{m}$ under the spray pressures of 30, 40 and 50 psi, respectively. At the same time, the extreme range of Dv0.9 by the nozzle 11006 first increased then decreased with the increase of spray pressure in the middle and low airflow 
velocity, which was the same as the nozzle 11006 with the largest difference analyzed in Dv0.5. Similarly, further statistical analysis showed that this trend was only applicable to the nozzle 11006, not applicable to the other types of nozzles, and the other four types of

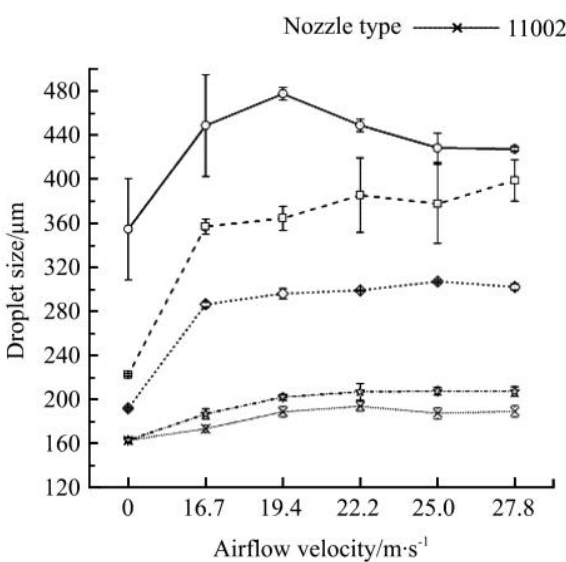

a. Spraying pressure of $30 \mathrm{psi}$ nozzles did not show any regular trends, which were not statistically significant and will not be listed here too.

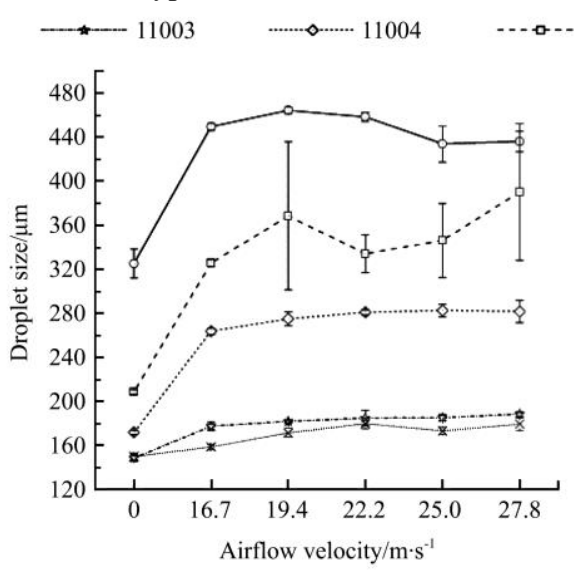

b. Spraying pressure of $40 \mathrm{psi}$

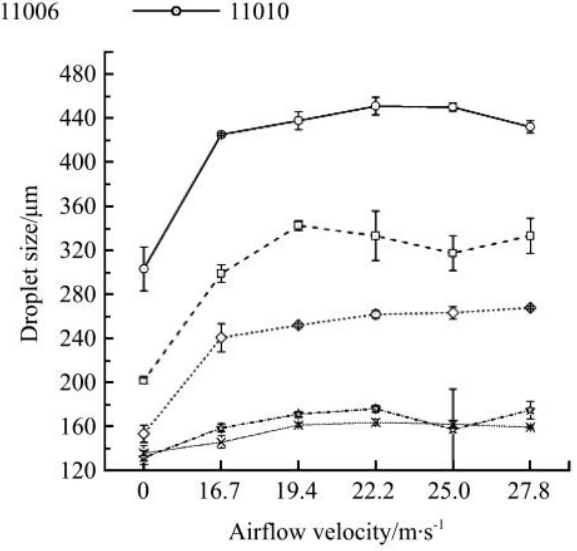

c. Spraying pressure of $50 \mathrm{psi}$

Figure 6 Variation of Dv0.5 with airflow velocity

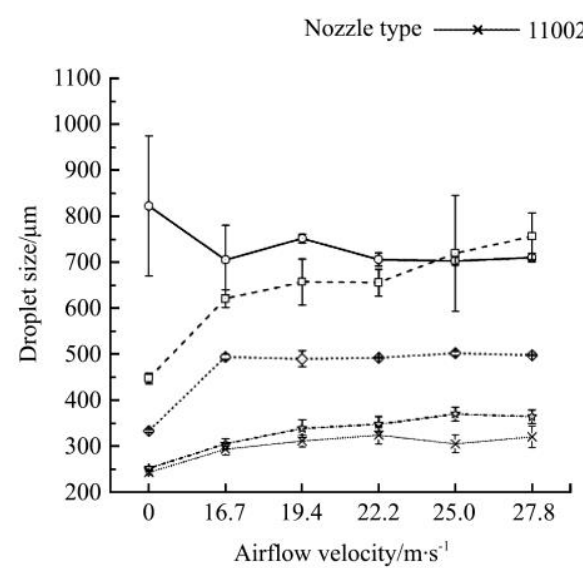

a. Spraying pressure of $30 \mathrm{psi}$

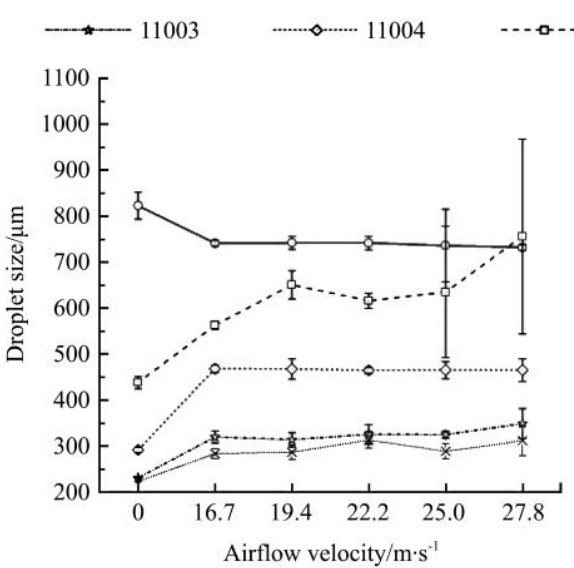

b. Spraying pressure of $40 \mathrm{ps}$

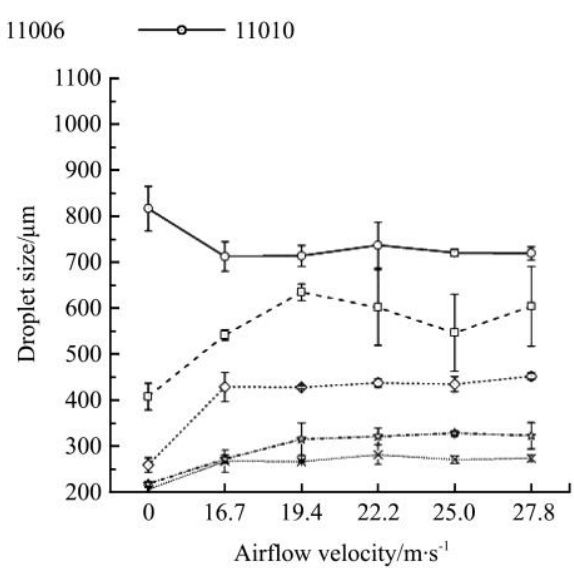

c. Spraying pressure of $50 \mathrm{psi}$

Figure 7 Variation of Dv0.9 with airflow velocity

The possible reasons for the above result are analyzed as follows:

1. Each type of nozzle is not the standard reference nozzle used for precision testing, limited by the processing accuracy error, some nozzles had larger deviations in droplets size measurement during the test, which in turn affected the final result. For example, at the airflow velocity of $19.4 \mathrm{~m} / \mathrm{s}$ (Figure 6b), the Dv0.5 standard deviation of nozzle 11006 was up to $67.5 \mu \mathrm{m}$ for three repeated measurements, and at the airflow velocity of $27.8 \mathrm{~m} / \mathrm{s}$ (Figure 7b), its up to $210.9 \mu \mathrm{m}$, which would affect the acquisition of the true spray characteristics of the nozzle 11006 with the various airflow velocities.

2. The formation of droplets on the pressure nozzle depended on the fracture of the flat liquid film ${ }^{[23]}$. With the airflow velocity increased, the air shear force of the flat liquid film was gradually increased, and the droplets were more likely to be broken and secondary broken, thereby changing the droplets size. At the same time, accompanied by the effect of droplet dispersion and the aggregation, the interaction of the two effects on the droplets would also cause a series of uncontrollable changes in size.

3. This is a result of the sampling bias with LDD. The laser measurement method of the LDD has limitations under different airflow conditions. The instrument used the optical detection method to count the particles in a specific space and then determined the size of the droplet size. Under no or low air velocities, the small droplets will be measured multiple times and result in smaller droplet size measurements, thus the measured particle size was larger with the airflow velocity increased. Due to the difference in the proportional value of each droplet volume parameter, this phenomenon was obvious for each type of nozzle in Dv0.5 (Figure 6), and only partially reflected by the nozzles in Dv0.1 (Figure 5) and Dv0.9 (Figure 7) ${ }^{[28-30] .}$

\subsection{Effect of spray pressure on spray parameters of various nozzles}

In order to further investigate the influence of spray pressure on spray parameters, the droplets size of each type of test nozzle under three different spray pressures is compared and analyzed. Fig. $8 \mathrm{a}$ to $8 \mathrm{f}$ show the comparison results for six different airflow velocities. It can be seen from the comparison that the Dvo.1, Dv0.5 and Dv0.9 of nozzle 11002, 11003, 11004 and 11006 were gradually decreasing with the spray pressure increased. Especially at airflow velocity of $0 \mathrm{~m} / \mathrm{s}$ (Figure $8 \mathrm{a}$ ), nozzles 11002 , 11003 and 11004 with smaller orifice size showed significant differences under three spray pressures, which indicated that the droplets size of the nozzle with small orifice size was easily 
affected by spray pressure. It can also be found that the effect of spray pressure on the droplets size of nozzle 11010 was not obvious, which with the largest orifice size, only Dv0.1 and Dv0.5 met this trend under low-speed airflow conditions of $0 \mathrm{~m} / \mathrm{s}$ (Figure

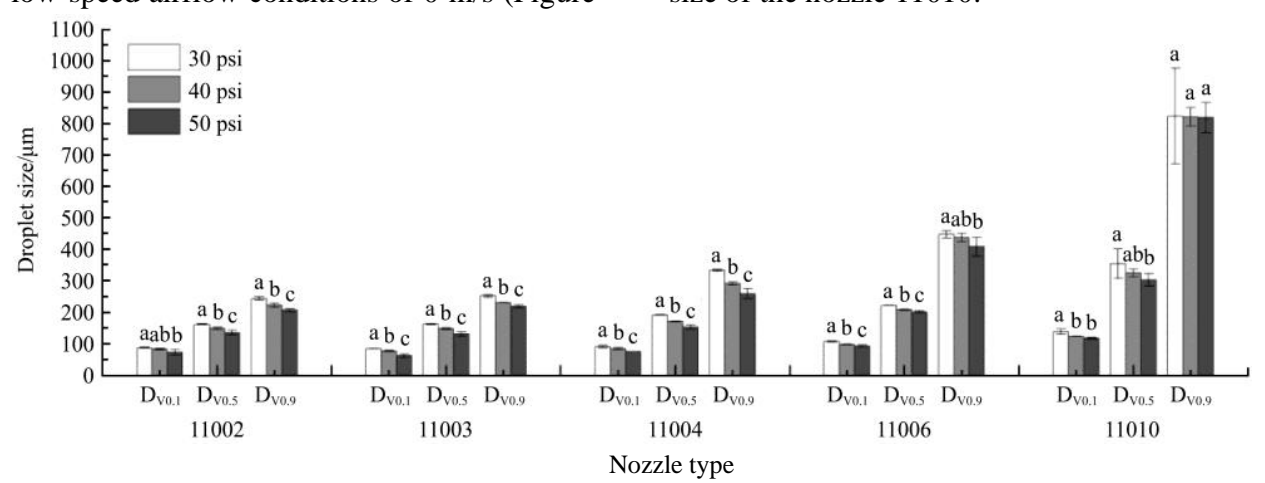

a. Airflow velocity of $0 \mathrm{~m} / \mathrm{s}$

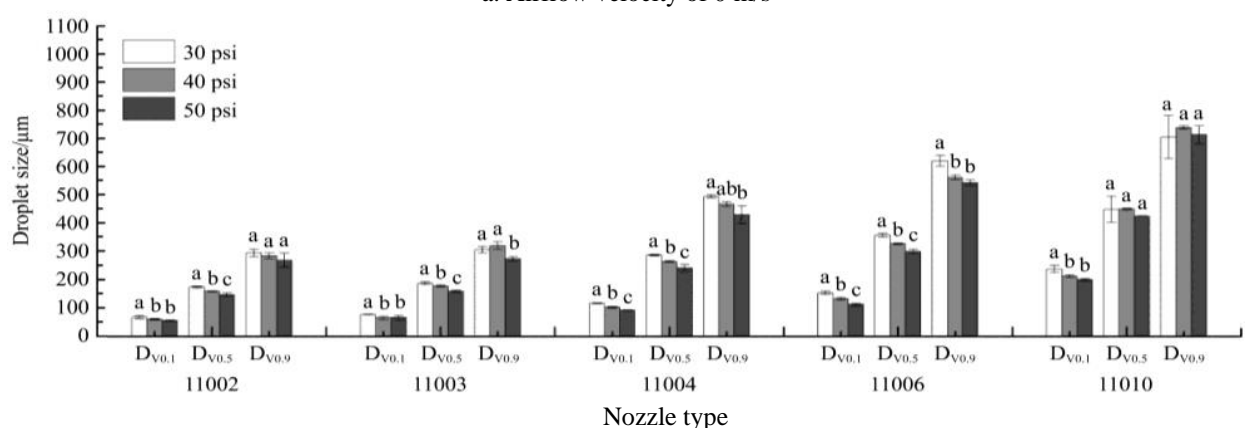

b. Airflow velocity of $16.7 \mathrm{~m} / \mathrm{s}$

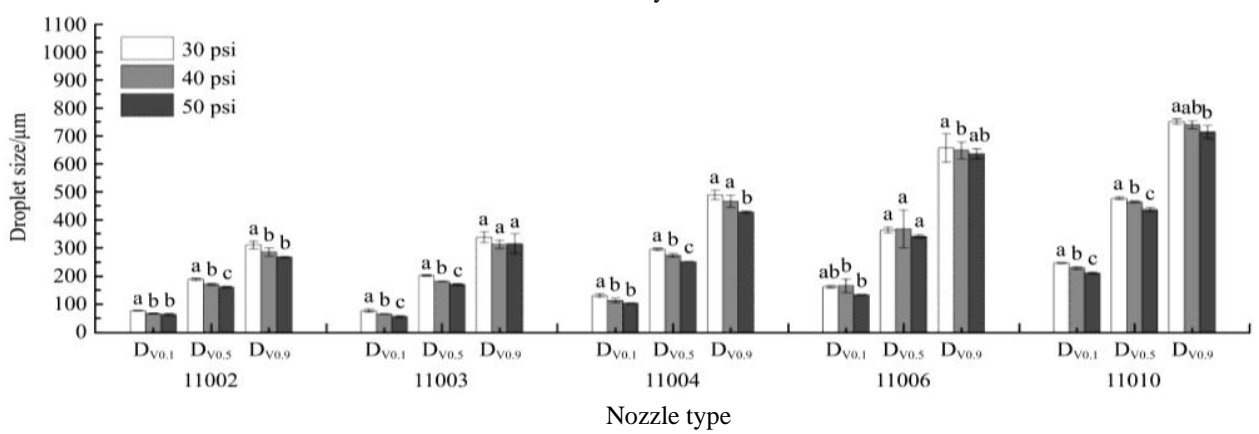

c. Airflow velocity of $19.4 \mathrm{~m} / \mathrm{s}$

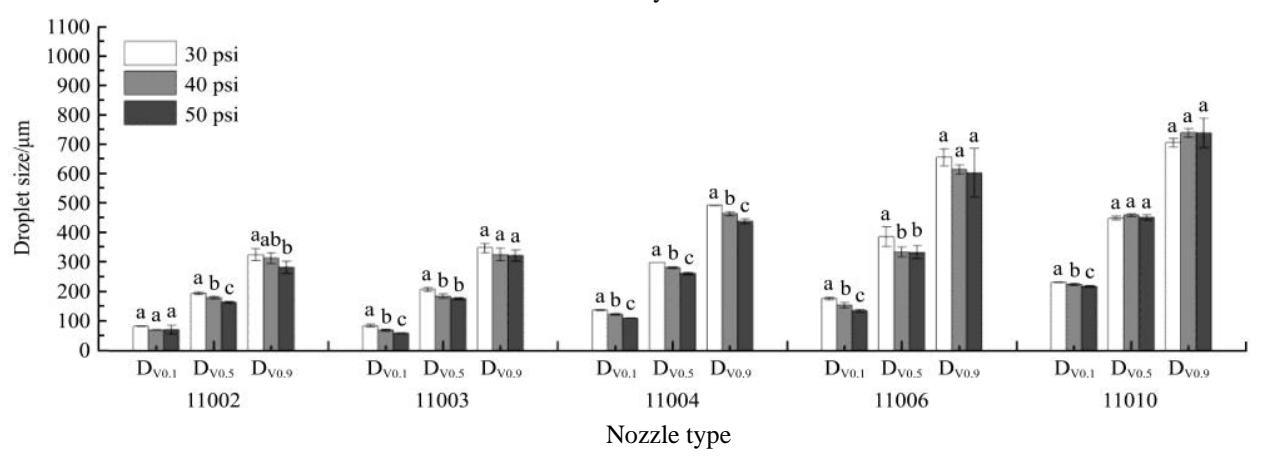

d. Airflow velocity of $22.2 \mathrm{~m} / \mathrm{s}$

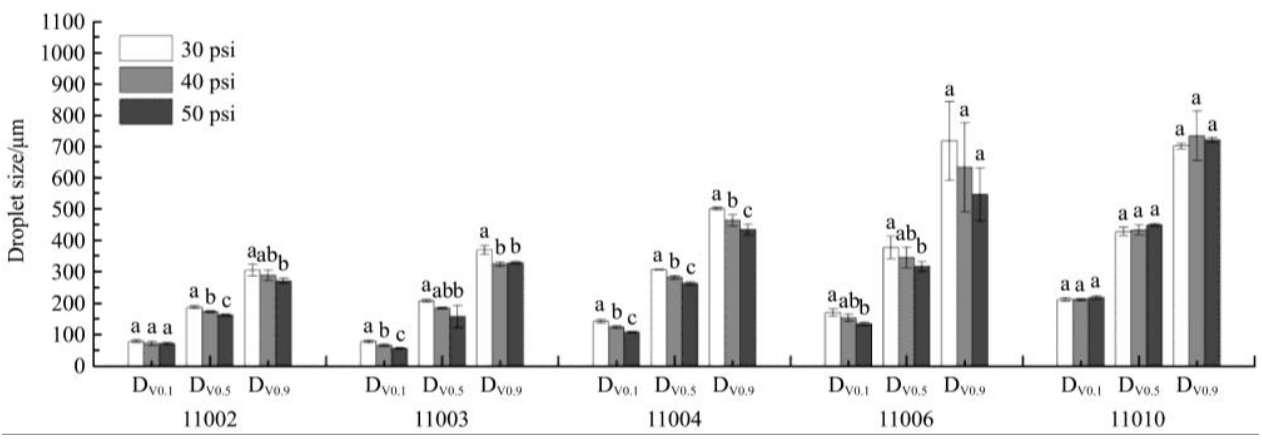




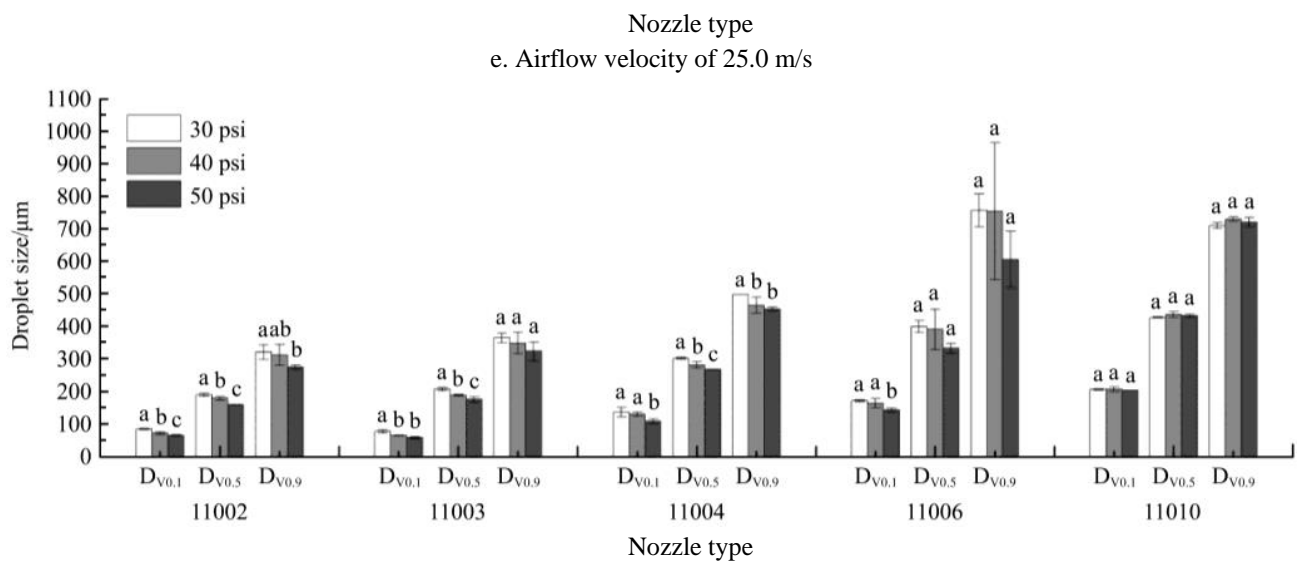

f. Airflow velocity of $27.8 \mathrm{~m} / \mathrm{s}$

Figure 8 Droplet size test results for each type of nozzle under three spray pressure

$\mathrm{SV}, \mathrm{V}_{<100}$ (\%volume) and RS for each nozzle within each classification category for each measurement airflow velocity (Table 3-8) are given below. By counting the values of spray parameters at each airflow velocity, it can be found that $89 \%$ of the SV was in the range of less than $15 \%$, which was similar to the results of Womac ${ }^{[31]}$ and Fritz's ${ }^{[26]}$ research. This indicated that in most cases the spraying performance of each type of nozzle was relatively stable. However, there were also a small number of SV were larger, and the maximum value was up to $55.9 \%$ (Bold font marked in Table 8). These values can be judged as obvious outliers due to the large deviation of the spray during repeated testing under some conditions, which was unavoidable for non-reference nozzles. This also maybe caused by the instrument's measurement such as drips from the nozzle or contamination of the lens on the laser. By observing $\mathrm{V}_{<100}$ (\%volume), it can be found that with the increase of spray pressure, the proportion of small droplets of nozzles 11002, 11003, 11004 and 11006 were gradually increasing, nozzle 11010 only had the same regular under the condition of low airflow velocity of 0$19.4 \mathrm{~m} / \mathrm{s}$. In addition, for the same type of nozzle, as the airflow velocity increased, the proportion of small droplets showed an irregular change, which was consistent with the pressure change analysis result shown in Figure 8 above. It can also be explained by the reason analyzed in 3.2 .

Table 3 Related parameters data for spray of each test nozzle at $0 \mathrm{~m} / \mathrm{s}$

\begin{tabular}{|c|c|c|c|c|c|c|c|}
\hline \multirow{2}{*}{$\begin{array}{l}\text { Nozzle } \\
\text { type }\end{array}$} & \multirow{2}{*}{$\begin{array}{l}\text { Pressure } \\
\quad / \mathrm{psi}\end{array}$} & \multicolumn{3}{|c|}{$\mathrm{SV} / \%$} & \multirow{2}{*}{$\begin{array}{c}\mathrm{V}_{<100} \\
\left(\%_{\text {volume }}\right)\end{array}$} & \multirow{2}{*}{ RS } & \multirow{2}{*}{ DSC } \\
\hline & & $\mathrm{Dv}_{0.1}$ & $\mathrm{Dv}_{0.5}$ & $\mathrm{Dv}_{0.9}$ & & & \\
\hline \multirow{3}{*}{11002} & 30 & 5.7 & 1.9 & 3.9 & $17.2 \pm 1.1 \mathrm{~b}$ & $0.95 \pm 0.03 \mathrm{a}$ & $\mathrm{VF} / \mathrm{F}$ \\
\hline & 40 & 5.3 & 4.3 & 5.8 & $20.7 \pm 2.3 b$ & $0.93 \pm 0.04 \mathrm{a}$ & $\mathrm{VF} / \mathrm{F}$ \\
\hline & 50 & 21.6 & 9.8 & 4.2 & $28.2 \pm 4.4 \mathrm{a}$ & $0.99 \pm 0.09 \mathrm{a}$ & $\mathrm{VF} / \mathrm{F}$ \\
\hline \multirow{3}{*}{11003} & 30 & 1.2 & 3.1 & 3.8 & $18.0 \pm 0.4 \mathrm{~b}$ & $1.02 \pm 0.02 \mathrm{~b}$ & $\mathrm{~F}$ \\
\hline & 40 & 4.2 & 3.8 & 0.7 & $21.9 \pm 0.6 \mathrm{~b}$ & $1.04 \pm 0.01 \mathrm{~b}$ & $\mathrm{VF} / \mathrm{F}$ \\
\hline & 50 & 14.2 & 9.1 & 4.4 & $32.0 \pm 4.6 \mathrm{a}$ & $1.18 \pm 0.07 \mathrm{a}$ & VF \\
\hline \multirow{3}{*}{11004} & 30 & 7.5 & 1.1 & 2.1 & $14.5 \pm 1.4 \mathrm{c}$ & $1.26 \pm 0.02 \mathrm{a}$ & $\mathrm{F}$ \\
\hline & 40 & 7.0 & 1.9 & 3.8 & $18.1 \pm 1.6 \mathrm{~b}$ & $1.20 \pm 0.03 \mathrm{ab}$ & $\mathrm{F}$ \\
\hline & 50 & 0.6 & 9.0 & 10.9 & $24.4 \pm 1.2 \mathrm{a}$ & $1.20 \pm 0.05 \mathrm{~b}$ & $\mathrm{~F}$ \\
\hline \multirow{3}{*}{11006} & 30 & 2.8 & 1.1 & 5.0 & $9.0 \pm 0.4 \mathrm{c}$ & $1.53 \pm 0.05 \mathrm{a}$ & $\mathrm{F} / \mathrm{M}$ \\
\hline & 40 & 2.1 & 2.0 & 5.8 & $11.7 \pm 0.3 \mathrm{~b}$ & $1.63 \pm 0.05 \mathrm{a}$ & $\mathrm{F}$ \\
\hline & 50 & 6.2 & 2.4 & 14.0 & $13.0 \pm 0.7 \mathrm{a}$ & $1.56 \pm 0.12 \mathrm{a}$ & $\mathrm{F}$ \\
\hline \multirow{3}{*}{11010} & 30 & 12.2 & 23.4 & 36.4 & $4.9 \pm 0.9 \mathrm{~b}$ & $1.92 \pm 0.2 \mathrm{~b}$ & $\mathrm{C} / \mathrm{VC}$ \\
\hline & 40 & 0.8 & 8.1 & 6.7 & $6.3 \pm 0.1 \mathrm{a}$ & $2.14 \pm 0.05 \mathrm{ab}$ & $\mathrm{C} / \mathrm{VC}$ \\
\hline & 50 & 5.4 & 13.0 & 11.7 & $7.5 \pm 0.7 \mathrm{a}$ & $2.31 \pm 0.04 \mathrm{a}$ & $\mathrm{C} / \mathrm{VC}$ \\
\hline
\end{tabular}

Note: Means \pm standard deviations within each nozzle type and droplet size parameter grouping $\left(\mathrm{V}_{<100}, \mathrm{RS}\right)$ followed by the same letter are not significantly different as determine using SPSS $16.0(\alpha=0.05)$. Table 4 to 8 are the same.

Table 4 Related parameters data for spray of each test nozzle at $16.7 \mathrm{~m} / \mathrm{s}$

\begin{tabular}{|c|c|c|c|c|c|c|c|}
\hline \multirow{2}{*}{$\begin{array}{c}\text { Nozzle } \\
\text { type }\end{array}$} & \multirow{2}{*}{$\begin{array}{c}\text { Pressure } \\
\text { /psi }\end{array}$} & \multicolumn{3}{|c|}{$\mathrm{SV} / \%$} & \multirow{2}{*}{$\begin{array}{c}\mathrm{V}_{<100} \\
\left(\% \%_{\text {volume }}\right)\end{array}$} & \multirow{2}{*}{ RS } & \multirow{2}{*}{ DSC } \\
\hline & & $\mathrm{Dv}_{0.1}$ & $\mathrm{Dv}_{0.5}$ & $\mathrm{Dv}_{0.9}$ & & & \\
\hline \multirow{3}{*}{11002} & 30 & 14.4 & 3.7 & 8.0 & $23.8 \pm 1.0 \mathrm{c}$ & $1.31 \pm 0.08 \mathrm{a}$ & $\mathrm{F}$ \\
\hline & 40 & 8.3 & 2.2 & 6.6 & $27.9 \pm 0.4 \mathrm{~b}$ & $1.42 \pm 0.05 \mathrm{a}$ & $\mathrm{VF} / \mathrm{F}$ \\
\hline & 50 & 8.6 & 7.8 & 16.7 & $31.5 \pm 2.4 \mathrm{a}$ & $1.46 \pm 0.12 \mathrm{a}$ & $\mathrm{VF} / \mathrm{F}$ \\
\hline \multirow{3}{*}{11003} & 30 & 4.0 & 5.0 & 7.5 & $18.3 \pm 0.5 \mathrm{c}$ & $1.23 \pm 0.06 \mathrm{~b}$ & $\mathrm{~F}$ \\
\hline & 40 & 16.2 & 3.8 & 7.1 & $23.3 \pm 1.1 \mathrm{~b}$ & $1.44 \pm 0.07 \mathrm{a}$ & $\mathrm{F}$ \\
\hline & 50 & 20.7 & 4.4 & 6.2 & $27.2 \pm 1.5 \mathrm{a}$ & $1.31 \pm 0.10 \mathrm{ab}$ & $\mathrm{F}$ \\
\hline \multirow{3}{*}{11004} & 30 & 3.2 & 1.5 & 2.3 & $8.1 \pm 0.3 \mathrm{c}$ & $1.32 \pm 0.01 \mathrm{~b}$ & M \\
\hline & 40 & 7.1 & 2.1 & 3.2 & $10.4 \pm 0.7 \mathrm{~b}$ & $1.39 \pm 0.01 \mathrm{a}$ & $\mathrm{F} / \mathrm{M}$ \\
\hline & 50 & 3.1 & 10.1 & 13.8 & $12.8 \pm 0.7 \mathrm{a}$ & $1.40 \pm 0.06 \mathrm{a}$ & $\mathrm{F}$ \\
\hline \multirow{3}{*}{11006} & 30 & 7.2 & 3.9 & 6.2 & $4.8 \pm 0.6 \mathrm{c}$ & $1.31 \pm 0.06 \mathrm{~b}$ & $\mathrm{M} / \mathrm{C}$ \\
\hline & 40 & 6.9 & 2.0 & 2.9 & $6.4 \pm 0.5 \mathrm{~b}$ & $1.32 \pm 0.02 \mathrm{~b}$ & M \\
\hline & 50 & 7.7 & 5.1 & 3.7 & $8.8 \pm 0.6 \mathrm{a}$ & $1.44 \pm 0.02 \mathrm{a}$ & M \\
\hline \multirow{3}{*}{11010} & 30 & 10.1 & 18.2 & 19.0 & $0.9 \pm 0.0 \mathrm{c}$ & $1.04 \pm 0.04 \mathrm{~b}$ & $\mathrm{C} / \mathrm{VC}$ \\
\hline & 40 & 4.3 & 1.3 & 1.5 & $1.9 \pm 0.2 \mathrm{~b}$ & $1.17 \pm 0.03 \mathrm{a}$ & $\mathrm{C} / \mathrm{VC}$ \\
\hline & 50 & 4.3 & 0.5 & 8.1 & $2.4 \pm 0.3 \mathrm{a}$ & $1.21 \pm 0.06 \mathrm{a}$ & $\mathrm{C}$ \\
\hline
\end{tabular}

Table 5 Related parameters data for spray of each test nozzle at $19.4 \mathrm{~m} / \mathrm{s}$

\begin{tabular}{|c|c|c|c|c|c|c|c|}
\hline \multirow{2}{*}{$\begin{array}{c}\text { Nozzle } \\
\text { type }\end{array}$} & \multirow{2}{*}{$\begin{array}{l}\text { Pressure } \\
\text { /psi }\end{array}$} & \multicolumn{3}{|c|}{$\mathrm{SV} / \%$} & \multirow{2}{*}{$\begin{array}{c}\mathrm{V}_{<100} \\
\left(\%_{\text {volume }}\right)\end{array}$} & \multirow{2}{*}{ RS } & \multirow{2}{*}{ DSC } \\
\hline & & $\mathrm{Dv}_{0.1}$ & $\mathrm{Dv}_{0.5}$ & $\mathrm{Dv}_{0.9}$ & & & \\
\hline \multirow{3}{*}{11002} & 30 & 3.8 & 4.7 & 8.0 & $18.9 \pm 0.9 \mathrm{c}$ & $1.24 \pm 0.03 \mathrm{a}$ & $\mathrm{F}$ \\
\hline & 40 & 6.0 & 4.6 & 10.3 & $23.7 \pm 1.2 \mathrm{~b}$ & $1.28 \pm 0.06 \mathrm{a}$ & F \\
\hline & 50 & 9.1 & 2.0 & 1.7 & $26.5 \pm 0.6 \mathrm{a}$ & $1.26 \pm 0.04 \mathrm{a}$ & F \\
\hline \multirow{3}{*}{11003} & 30 & 13.7 & 2.3 & 11.4 & $17.4 \pm 1.2 \mathrm{c}$ & $1.29 \pm 0.09 \mathrm{a}$ & F \\
\hline & 40 & 4.1 & 1.2 & 9.0 & $22.0 \pm 0.2 \mathrm{~b}$ & $1.37 \pm 0.07 \mathrm{a}$ & F \\
\hline & 50 & 11.7 & 2.4 & 21.1 & $25.8 \pm 1.0 \mathrm{a}$ & $1.51 \pm 0.21 \mathrm{a}$ & $\mathrm{VF} / \mathrm{F}$ \\
\hline \multirow{3}{*}{11004} & 30 & 9.6 & 2.7 & 6.5 & $5.1 \pm 1.7 \mathrm{~b}$ & $1.21 \pm 0.06 \mathrm{a}$ & M \\
\hline & 40 & 12.6 & 4.3 & 8.3 & $7.8 \pm 1.8 \mathrm{ab}$ & $1.28 \pm 0.08 \mathrm{a}$ & $\mathrm{F} / \mathrm{M}$ \\
\hline & 50 & 2.3 & 0.9 & 1.8 & $9.7 \pm 0.3 \mathrm{a}$ & $1.29 \pm 0.01 \mathrm{a}$ & F \\
\hline \multirow{2}{*}{11006} & 30 & 6.2 & 5.2 & 13.5 & $3.8 \pm 0.8 \mathrm{~b}$ & $1.36 \pm 0.17 \mathrm{~b}$ & $\mathrm{M} / \mathrm{C}$ \\
\hline & 40 & 29.2 & 31.7 & 8.4 & $4.0 \pm 1.4 \mathrm{~b}$ & $1.34 \pm 0.24 \mathrm{ab}$ & $\mathrm{M} / \mathrm{C}$ \\
\hline
\end{tabular}




\begin{tabular}{cccccccc} 
& 50 & 2.0 & 2.5 & 5.1 & $6.3 \pm 0.2 \mathrm{a}$ & $1.47 \pm 0.07 \mathrm{a}$ & $\mathrm{M} / \mathrm{C}$ \\
\hline \multirow{4}{*}{11010} & 30 & 1.8 & 2.1 & 2.5 & $0.8 \pm 0.1 \mathrm{c}$ & $1.06 \pm 0.01 \mathrm{~b}$ & $\mathrm{C} / \mathrm{VC}$ \\
& 40 & 3.6 & 1.3 & 3.7 & $1.4 \pm 0.1 \mathrm{~b}$ & $1.10 \pm 0.03 \mathrm{ab}$ & $\mathrm{C} / \mathrm{VC}$ \\
& 50 & 3.3 & 3.7 & 6.3 & $2.0 \pm 0.4 \mathrm{a}$ & $1.15 \pm 0.04 \mathrm{a}$ & $\mathrm{C} / \mathrm{VC}$ \\
\hline
\end{tabular}

Table 6 Related parameters data for spray of each test nozzle at $22.2 \mathrm{~m} / \mathrm{s}$

\begin{tabular}{|c|c|c|c|c|c|c|c|}
\hline \multirow{2}{*}{$\begin{array}{l}\text { Nozzle } \\
\text { type }\end{array}$} & \multirow{2}{*}{$\begin{array}{l}\text { Pressure } \\
\quad / \mathrm{psi}\end{array}$} & \multicolumn{3}{|c|}{$\mathrm{SV} / \%$} & \multirow{2}{*}{$\begin{array}{c}\mathrm{V}_{<100} \\
(\% \text { volume })\end{array}$} & \multirow{2}{*}{$\mathrm{RS}$} & \multirow{2}{*}{ DSC } \\
\hline & & $\mathrm{Dv}_{0.1}$ & $\mathrm{Dv}_{0.5}$ & $\mathrm{Dv}_{0.9}$ & & & \\
\hline \multirow{3}{*}{11002} & 30 & 2.8 & 4.0 & 11.7 & $17.1 \pm 0.9 \mathrm{~b}$ & $1.25 \pm 0.07 \mathrm{a}$ & F \\
\hline & 40 & 2.3 & 5.3 & 11.3 & $22.0 \pm 1.0 \mathrm{a}$ & $1.36 \pm 0.06 \mathrm{a}$ & $\mathrm{F}$ \\
\hline & 50 & 40.4 & 2.9 & 13.5 & $25.2 \pm 2.9 \mathrm{a}$ & $1.29 \pm 0.21 \mathrm{a}$ & $\mathrm{F}$ \\
\hline \multirow{3}{*}{11003} & 30 & 9.0 & 6.3 & 8.7 & $15.8 \pm 1.2 \mathrm{c}$ & $1.28 \pm 0.02 \mathrm{~b}$ & $\mathrm{~F}$ \\
\hline & 40 & 8.4 & 7.4 & 12.9 & $20.9 \pm 0.5 \mathrm{~b}$ & $1.39 \pm 0.08 \mathrm{ab}$ & $\mathrm{F}$ \\
\hline & 50 & 4.8 & 3.0 & 11.2 & $25.2 \pm 0.2 \mathrm{a}$ & $1.49 \pm 0.08 \mathrm{a}$ & $\mathrm{VF} / \mathrm{F}$ \\
\hline \multirow{3}{*}{11004} & 30 & 2.9 & 0.2 & 0.3 & $4.2 \pm 0.3 \mathrm{c}$ & $1.19 \pm 0.01 \mathrm{~b}$ & $\mathrm{M}$ \\
\hline & 40 & 4.2 & 1.5 & 2.6 & $6.1 \pm 0.6 \mathrm{~b}$ & $1.21 \pm 0.02 \mathrm{~b}$ & M \\
\hline & 50 & 1.4 & 2.5 & 4.1 & $8.6 \pm 0.2 \mathrm{a}$ & $1.25 \pm 0.02 \mathrm{a}$ & $\mathrm{F} / \mathrm{M}$ \\
\hline \multirow{3}{*}{11006} & 30 & 4.4 & 17.6 & 8.6 & $3.7 \pm 0.1 \mathrm{c}$ & $1.25 \pm 0.08 \mathrm{a}$ & $\mathrm{M} / \mathrm{C}$ \\
\hline & 40 & 11.7 & 10.2 & 4.8 & $4.9 \pm 0.6 \mathrm{~b}$ & $1.38 \pm 0.06 \mathrm{a}$ & $\mathrm{M} / \mathrm{C}$ \\
\hline & 50 & 6.0 & 12.7 & 27.1 & $6.3 \pm 0.3 \mathrm{a}$ & $1.40 \pm 0.15 \mathrm{a}$ & $\mathrm{M} / \mathrm{C}$ \\
\hline \multirow{3}{*}{11010} & 30 & 1.1 & 2.4 & 4.1 & $1.2 \pm 0.2 \mathrm{a}$ & $1.06 \pm 0.04 \mathrm{a}$ & $\mathrm{C} / \mathrm{VC}$ \\
\hline & 40 & 2.9 & 1.7 & 3.8 & $1.6 \pm 0.4 \mathrm{a}$ & $1.12 \pm 0.05 \mathrm{a}$ & $\mathrm{C} / \mathrm{VC}$ \\
\hline & 50 & 2.2 & 3.6 & 12.5 & $1.5 \pm 0.4 \mathrm{a}$ & $1.15 \pm 0.09 \mathrm{a}$ & $\mathrm{C} / \mathrm{VC}$ \\
\hline
\end{tabular}

Table 7 Related parameters data for spray of each test nozzle at $25.0 \mathrm{~m} / \mathrm{s}$

\begin{tabular}{|c|c|c|c|c|c|c|c|}
\hline \multirow{2}{*}{$\begin{array}{l}\text { Nozzle } \\
\text { type }\end{array}$} & \multirow{2}{*}{$\begin{array}{l}\text { Pressure } \\
\text { /psi }\end{array}$} & \multicolumn{3}{|c|}{ SV/\% } & \multirow{2}{*}{$\begin{array}{c}\mathrm{V}_{<100} \\
(\% \text { volume })\end{array}$} & \multirow{2}{*}{$\mathrm{RS}$} & \multirow{2}{*}{ DSC } \\
\hline & & $\mathrm{Dv}_{0.1}$ & $\mathrm{Dv}_{0.5}$ & $\mathrm{Dv}_{0.9}$ & & & \\
\hline \multirow{3}{*}{11002} & 30 & 10.6 & 5.3 & 12.3 & $19.0 \pm 1.4 \mathrm{c}$ & $1.21 \pm 0.09 \mathrm{a}$ & $\mathrm{F}$ \\
\hline & 40 & 18.8 & 3.5 & 10.4 & $23.2 \pm 0.8 \mathrm{~b}$ & $1.26 \pm 0.12 \mathrm{a}$ & F \\
\hline & 50 & 10.6 & 3.9 & 6.1 & $25.3 \pm 0.6 \mathrm{a}$ & $1.24 \pm 0.03 \mathrm{a}$ & $\mathrm{F}$ \\
\hline \multirow{3}{*}{11003} & 30 & 11.1 & 3.2 & 6.9 & $16.6 \pm 1.2 \mathrm{c}$ & $1.41 \pm 0.07 \mathrm{a}$ & F \\
\hline & 40 & 9.8 & 2.8 & 3.9 & $22.0 \pm 1.5 \mathrm{~b}$ & $1.40 \pm 0.01 \mathrm{a}$ & $\mathrm{F}$ \\
\hline & 50 & 5.8 & 40.3 & 2.3 & $26.0 \pm 0.5 \mathrm{a}$ & $1.81 \pm 0.46 \mathrm{a}$ & $\mathrm{VF} / \mathrm{F}$ \\
\hline \multirow{3}{*}{11004} & 30 & 7.8 & 0.6 & 1.7 & $4.0 \pm 0.8 \mathrm{c}$ & $1.17 \pm 0.03 \mathrm{a}$ & M \\
\hline & 40 & 6.0 & 3.9 & 7.8 & $6.0 \pm 0.8 \mathrm{~b}$ & $1.20 \pm 0.05 \mathrm{a}$ & M \\
\hline & 50 & 5.4 & 4.1 & 7.2 & $9.3 \pm 0.5 \mathrm{a}$ & $1.25 \pm 0.04 \mathrm{a}$ & $\mathrm{F} / \mathrm{M}$ \\
\hline \multirow{3}{*}{11006} & 30 & 13.0 & 19.0 & 34.7 & $3.9 \pm 0.6 \mathrm{c}$ & $1.44 \pm 0.17 \mathrm{a}$ & $\mathrm{M} / \mathrm{C}$ \\
\hline & 40 & 15.2 & 19.2 & 44.8 & $5.1 \pm 0.7 \mathrm{~b}$ & $1.37 \pm 0.24 \mathrm{a}$ & $\mathrm{M} / \mathrm{C}$ \\
\hline & 50 & 6.0 & 9.7 & 29.7 & $6.3 \pm 0.4 \mathrm{a}$ & $1.29 \pm 0.19 \mathrm{a}$ & $\mathrm{M} / \mathrm{C}$ \\
\hline \multirow{3}{*}{11010} & 30 & 4.2 & 6.0 & 2.4 & $1.9 \pm 0.4 \mathrm{a}$ & $1.15 \pm 0.07 \mathrm{a}$ & $\mathrm{C} / \mathrm{VC}$ \\
\hline & 40 & 3.1 & 6.9 & 19.1 & $2.0 \pm 0.2 \mathrm{a}$ & $1.20 \pm 0.13 \mathrm{a}$ & $\mathrm{C} / \mathrm{VC}$ \\
\hline & 50 & 4.3 & 1.5 & 2.1 & $1.6 \pm 0.4 \mathrm{a}$ & $1.12 \pm 0.03 \mathrm{a}$ & $\mathrm{C} / \mathrm{VC}$ \\
\hline
\end{tabular}

Table 8 Related parameters data for spray of each test nozzle at $27.8 \mathrm{~m} / \mathrm{s}$

\begin{tabular}{|c|c|c|c|c|c|c|c|}
\hline \multirow{2}{*}{$\begin{array}{l}\text { Nozzle } \\
\text { type }\end{array}$} & \multirow{2}{*}{$\begin{array}{l}\text { Pressure } \\
\text { /psi }\end{array}$} & \multicolumn{3}{|c|}{$\mathrm{SV} / \%$} & \multirow{2}{*}{$\begin{array}{c}\mathrm{V}_{<100} \\
\left(\%_{\text {volume }}\right)\end{array}$} & \multirow{2}{*}{$\mathrm{RS}$} & \multirow{2}{*}{ DSC } \\
\hline & & $\mathrm{Dv}_{0.1}$ & $\mathrm{Dv}_{0.5}$ & $\mathrm{Dv}_{0.9}$ & & & \\
\hline \multirow{3}{*}{11002} & 30 & 5.5 & 5.6 & 14.1 & $16.5 \pm 1.0 \mathrm{c}$ & $1.25 \pm 0.08 \mathrm{a}$ & $\mathrm{F}$ \\
\hline & 40 & 13.8 & 6.4 & 20.7 & $22.5 \pm 0.9 \mathrm{~b}$ & $1.34 \pm 0.16 \mathrm{a}$ & F \\
\hline & 50 & 6.3 & 1.1 & 4.5 & $27.3 \pm 0.0 \mathrm{a}$ & $1.32 \pm 0.05 \mathrm{a}$ & F \\
\hline \multirow{3}{*}{11003} & 30 & 12.3 & 3.9 & 7.7 & $16.8 \pm 1.0 \mathrm{c}$ & $1.39 \pm 0.12 \mathrm{a}$ & $\mathrm{F}$ \\
\hline & 40 & 3.0 & 1.9 & 18.5 & $22.0 \pm 0.8 \mathrm{~b}$ & $1.51 \pm 0.18 \mathrm{a}$ & $\mathrm{F}$ \\
\hline & 50 & 11.8 & 8.8 & 17.6 & $25.0 \pm 1.6 \mathrm{a}$ & $1.52 \pm 0.11 \mathrm{a}$ & $\mathrm{VF} / \mathrm{F}$ \\
\hline \multirow{3}{*}{11004} & 30 & 19.9 & 1.7 & 0.2 & $4.9 \pm 2.2 \mathrm{~b}$ & $1.20 \pm 0.06 \mathrm{a}$ & $\mathrm{M}$ \\
\hline & 40 & 9.3 & 7.1 & 10.2 & $5.1 \pm 1.7 \mathrm{~b}$ & $1.19 \pm 0.07 \mathrm{a}$ & M \\
\hline & 50 & 13.1 & 0.7 & 2.7 & $9.1 \pm 1.6 \mathrm{a}$ & $1.29 \pm 0.01 \mathrm{a}$ & $\mathrm{F} / \mathrm{M}$ \\
\hline 11006 & 30 & 4.4 & 8.9 & 13.5 & $3.8 \pm 0.1 \mathrm{~b}$ & $1.46 \pm 0.06 \mathrm{a}$ & $\mathrm{M} / \mathrm{C}$ \\
\hline
\end{tabular}

\begin{tabular}{cccccccc} 
& 40 & 17.2 & 31.8 & 55.9 & $4.6 \pm 0.8 \mathrm{~b}$ & $1.48 \pm 0.29 \mathrm{a}$ & $\mathrm{M} / \mathrm{C}$ \\
& 50 & 7.9 & 8.3 & 27.0 & $5.8 \pm 0.5 \mathrm{a}$ & $1.38 \pm 0.18 \mathrm{a}$ & $\mathrm{M} / \mathrm{C}$ \\
\hline \multirow{3}{*}{11010} & 30 & 1.6 & 0.8 & 2.6 & $2.4 \pm 0.1 \mathrm{a}$ & $1.18 \pm 0.02 \mathrm{a}$ & $\mathrm{C}$ \\
& 40 & 6.8 & 3.9 & 1.5 & $2.3 \pm 0.4 \mathrm{a}$ & $1.20 \pm 0.04 \mathrm{a}$ & $\mathrm{C}$ \\
& 50 & 0.2 & 2.4 & 3.7 & $2.1 \pm 0.0 \mathrm{a}$ & $1.19 \pm 0.02 \mathrm{a}$ & $\mathrm{C}$ \\
\hline
\end{tabular}

For RS, it can be known from the analysis that the spray pressure had not significant effect on the RS of nozzle 11002, but had a slight influence on other types of nozzles. As the airflow velocity increased, the influence gradually weakened, especially at the airflow velocity of $27.8 \mathrm{~m} / \mathrm{s}$, the spray pressure had not significant effect on the RS of each type of nozzle. Finally, the analysis of the DSC showed that for the same type of nozzle, the DSC rating of droplets at a spray pressure of 50 psi were the highest. As the airflow velocity of the wind tunnel increased, the spray droplets size of each type of nozzle exhibited an unstable trend, only nozzle 11002 fluctuated minimally and was the most stable. However, it cannot be ruled out that the effect of sampling technique may also be part of the reason, which needs further confirmation.

Based on the above analysis, when designing and selecting aerial nozzle, the quality of the nozzle should be strictly controlled, and the droplet size parameters should be controlled within a suitable range to reduce the spray deviation, then achieving the optimal spray effect.

\section{Conclusions}

In this paper, the test of the LICHENG series of aerial nozzles was proceeded in the wind tunnel, the droplets size distribution of aerial nozzle adapted to manned agricultural helicopters under medium-low airflow velocity conditions was analyzed. At the same time, the droplet size and spray parameter difference of each type of nozzle in the wind tunnel under three different spray pressures were also compared. The conclusions are as follows:

(1) Under the three spray pressures of 30, 40 and $50 \mathrm{psi}$, the droplets size of the five types of nozzles 11002, 11003, 11004, 11006 and 11010 showed similar trends with the increase of airflow velocity. Among them, the droplet size difference of nozzles 11006 and 11010 with larger orifice sizes was the most significant. The largest range of $D_{v 0.1}$ was nozzle 11010 , with the corresponding range values up to $108.8,105.2$ and $100.5 \mu \mathrm{m}$. The most range of Dv0.5 was nozzle 11006, with the corresponding range values up to $176.9,182.0$ and $140.8 \mu \mathrm{m}$. The most range of Dv0.9 was nozzle 11006, with the corresponding range values up to $308.2,316.2$ and $227.4 \mu \mathrm{m}$, respectively.

(2) Under the condition of medium and low airflow velocity of $0-27.8 \mathrm{~m} / \mathrm{s}$, due to the manufacturing precision of test nozzle, the spray stability of some nozzles was affected during the test, which measured the droplets size value larger, and the largest value was up to $210.9 \mu \mathrm{m}$. There were certain deficiencies about the domestic nozzles used in this test, and the quality needs to be improved.

(3) Limitations existed in wind tunnel droplet size testing by using LDD, and an increase in airflow velocity resulted in a larger measurement droplet size. This phenomenon was particularly significant in the $\mathrm{D}_{\mathrm{v} 0.5}$ test results of various types of nozzles.

(4) Statistically, $89 \%$ of SV by the nozzle 11002, 11003, 11004, 11006 and 11010 were in the range of less than $15 \%$, indicating that the spraying performance of each type of nozzle was relatively stable under medium and low airflow velocity conditions.

(5) The change in spray pressure would directly affect the 
quality of spray. The droplet size of the nozzle 11002, 11003 and 11004 with small orifice size was significantly affected by the spray pressure. However, as the airflow velocity increased, the significance of spray pressure on the spraying effect of these nozzles was gradually weakened.

\section{Acknowledgments}

We deeply thank for the Guangdong Leading Talent Project (2016LJ06G689), National Key Technologies Research and Development Program (2016YFD0200700), 111 Project (D18019), Science and Technology Planning Project of Guangdong (2017B010117010). Thanks to the National Center for International Collaboration Research on Precision Agricultural Aviation Pesticides Spraying Technology for the full participation persons of the experiment (Zhang Quanyong, Shan Jian, Huang Xiaoyu, Han Jie, Yue Changquan, Wang Juan, Xu Weicheng). Thanks to Jiangxi Tianren Ecology Co., Ltd for strong support.

\section{[References]}

[1] Lan Y B, Chen S D, Fritz B K. Current status and future trends of precision agricultural aviation technologies. International Journal of Agricultural \& Biological Engineering, 2017; 10(3): 1-17. doi: 10.3965/j.ijabe.20171003.3088.

[2] Antuniassi U R, Motta A A B, Chechetto R G, et al. Spray drift from aerial application. Aspects of Applied Biology, 2014; (122): 279-284.

[3] Yao W X, Lan Y B, Wang J, et al. Droplet drift characteristics of aerial spraying of AS350B3e helicopter. Transactions of the CSAE, 2017; 33(22): 75-83. doi: 10.11975/j.issn.1002-6819.2017.22.010. (in Chinese)

[4] Hilz E, Vermeer A W P. Spray drift review: The extent to which a formulation can contribute to spray drift reduction. Crop Protection, 2013; 44(1): 75-83. doi: 10.1016/j.cropro.2012.10.020.

[5] Sudheer K P, Panda R K. Digital image processing for determining drop sizes from irrigation spray nozzles. Agricultural Water Management, 2000; 45(2): 159-167. doi:10.1016/S0378-3774(99)00079-7.

[6] Dorr G, Hanan J, Adkins S, et al. Spray deposition on plant surfaces: a modelling approach. Functional Plant Biology, 2008; 35(2): 988-996. doi: 10.1071/FP08056.

[7] Hewitt A J. Droplet size spectra classification categories in aerial application scenarios. Crop Protection, 2008; 27(9): 1284-1288. doi: 10.1016/j.cropro.2008.03.010.

[8] Yao W X, Wang X J, Lan Y B, et al. Effect of UAV prewetting application during the flowering period of cotton on pesticide droplet deposition. Frontiers of Agricultural Science and Engineering, 2018, 5(4): 455-461. doi: 10.15302/J-FASE-2018232.

[9] Chanetz B. A century of wind tunnels since Eiffel. Comptes Rendus Mécanique, 2017; 345(8), 581-594. doi: 10.1016/j.crme.2017.05.012.

[10] Guler H, Zhu H P, Ozkan H E, et al. Spray characteristics and drift reduction potential with air induction and conventional flat-fan nozzles. Transactions of the ASABE, 2007; 50(3): 745-754. doi: 10.13031/2013. 23129.

[11] Kirk I W. Measurement and prediction of atomization parameters from fixed-wing aircraft spray nozzles. Transactions of the ASABE, 2007; 50(3), 693-703. doi: 10.13031/2013.23123.

[12] Hoffmann W C, Hewitt A J, Ross J B, et al. Spray adjuvant effects on droplet size spectra measured by three laser-based systems in a high-speed wind tunnel. Journal of ASTM International, 2008; 5(6): 1-12. doi: 10.1520/STP46608S.

[13] Fritz B K, Hoffmann W C. Update to the USDA-ARS fixed-wind spray nozzle models. Transactions of the ASABE, 2015; 58(2): 281-295. doi: 10.13031/trans.58.10896.

[14] Fritz B K, Hoffmann W C, Kruger G R, et al. Comparison of drop size data from ground and aerial application nozzles at three testing laboratories. Atomization and sprays 2014; 24(2): 181-192. doi: 10.1615/AtomizSpr.
2013009668.

[15] Lan Y B, Chen S D. Current status and trends of plant protection UAV and its spraying technology in China. International Journal of Precision Agricultural Aviation, 2018; 1(1): 1-9. doi: 10.33440/j.ijpaa.20180101. 0002 .

[16] Yao W X, Lan Y B, Wen S, et al. Evaluation of droplet deposition and effect of variable-rate application by a manned helicopter with AG-NAV Guía system. International Journal of Agricultural \& Biological Engineering, 2019; 12(1): 172-178. doi: 10.25165/j.ijabe.20191201.4039.

[17] Zhang D Y, Chen L P, Zhang R R, et al. Evaluating effective swath width and droplet distribution of aerial spraying systems on M-18B and Thrush 510G airplanes. International Journal of Agricultural \& Biological Engineering, 2015; 8(2): 21-30. doi: 10.3965/j.ijabe.20150802.1493.

[18] Li J Y, Shi Y Y, Lan Y B, et al. Vertical distribution and vortex structure of rotor wind field under the influence of rice canopy. Computers and Electronics in Agriculture, 2019; (159): 140-146. doi: 10.1016/j.compag. 2019.02.027.

[19] Liu H S, Lan Y B, Xue X Y, et al. Development of wind tunnel test technologies in agricultural aviation spraying. Transactions of the CSAE, 2015; 31(Supp.2): 1-10. doi: 10.11975/j.issn.1002-6819.2015.z2.001. (in Chinese)

[20] Wang X N, He X K, Song J L, et al. Effect of adjuvant types and concentration on spray drift potential of different nozzles. Transactions of the CSAE, 2015; 31(22): 49-55. doi: 10.11975/j.issn.1002-6819.2015. 22.007. (in Chinese)

[21] Zhang R R, Li L L, Fu W, et al. Spraying atomization performance by pulse width modulated variable and droplet deposition characteristics in wind tunnel. Transactions of the CSAE, 2019; 35(3): 42-51. doi: 10.11975/j.issn.1002-6819.2019.03.006. (in Chinese)

[22] Zhang H C, Dorr G, Zheng J Q, et al. Wind tunnel experiment of influence on droplet size distribution of flat fan nozzles. Transactions of the CSAM, 2012; 43(6): 53-57+52. doi:10.6041/j.issn.1000-1298.2012. 06.010. (in Chinese)

[23] Tang Q, Chen L P, Zhang R R, et al. Atomization characteristics of normal flat fan nozzle and air induction nozzle under high speed airflow conditions. Transactions of the CSAE, 2016, 32(22): 121-128. doi: 10.11975/j.issn.1002-6819.2016.22.017. (in Chinese)

[24] Ru Y, Zhu C Y, Bao R, et al. Droplet size distribution of aerial nozzle for plant protection in wind tunnel and flight conditions. Transactions of the CSAE, 2016; 32(20): 94-98. doi: 10.11975/j.issn.1002-6819.2016.20.012. (in Chinese)

[25] ISO Standards, 22856: Equipment for crop protection-Methods for the laboratory measurement of spray drift-Wind tunnels, Geneva: International Organization for Standardization, 2008.

[26] Fritz B K, Hoffmann W C. Establishing reference nozzles for classification of aerial application spray technologies. International Journal of Precision Agricultural Aviation, 2018; 1(1): 10-14. doi: 10.33440/j.ijpaa.20180101.0003.

[27] ASAE Standards, S672.2: Spray nozzle classification by droplet spectra, St. Joseph, MI: American Society of Agricultural and Biological Engineers, 2018.

[28] Dodge L G, Rhodes D J, Reitz R D. Drop-size measurement techniques for sprays: comparison of malvern laser-diffraction and aerometrics phase/doppler. Applied Optics, 1987; 26(11): 2144-2154. doi: 10.1364/ AO.26.002144.

[29] Hoffmann W C, Fritz B K, Lan Y B. Using laser diffraction to measure agricultural sprays: common sources of error when making measurements. International Journal of Precision Agricultural Aviation, 2018; 1(1): 15-18. doi: 10.33440/j.ijpaa.20180101.0005.

[30] Fritz B K, Hoffmann W C, Bagley W E, et al. Measuring droplet size of agricultural spray nozzles-measurement distance and airspeed effects. Atomization and sprays, 2014; 24(9): 747-760. doi: 10.1615/AtomizSpr. 2014008424.

[31] Womac A R. Quality Control of Standardized Reference Spray Nozzles. Transactions of the ASAE, 2000; 43(1): 47-56. doi: 10.13031/2013.2686. 